\title{
HUBUNGAN PERAN AYAH ASI DENGAN PEMBERIAN ASI EKSKLUSIF
}

\author{
Asri Tresnaasih ${ }^{1}$, Reni ${ }^{2}$, Suci Najla ${ }^{3}$ \\ 1,2,3) Program Studi Diploma Kebidanan Fakultas Ilmu Kesehatan \\ Universitas 'Aisyiyah Bandung \\ asri.tresnaasih@gmail.com
}

\begin{abstract}
ABSTRAK
Cakupan bayi yang mendapatkan ASI secara eksklusif di Kabupaten Bandung tahun 2018 sebesar 50,39\%. Keberhasilan ibu dalam pemberian ASI Eksklusif dapat dipengaruhi oleh dukungan dari keluarga, terutama Ayah yang berperan sebagai ayah ASI. Ayah ASI merupakan keterlibatan seorang Ayah dalam memberikan dukungan, baik secara moril maupun material kepada istrinya dalam proses menyusui. Penelitian ini bertujuan mengetahui hubungan peran Ayah ASI dengan pemberian ASI eksklusif di Praktik Mandiri Bidan (PMB) Kabupaten Bandung. Rancangan penelitian menggunakan survei analitik dengan desain penelitian cross-sectional. Jumlah sampel sebanyak 67 responden yaitu ibu yang mempunyai bayi 6-12 bulan yang berkunjungan ke PMB Kabupaten Bandung. Pengumpulan data menggunakan kuesioner yang telah diuji validitas dan reliabilitas yang disebarkan dengan Google form melalui aplikasi WhatsApp. Data penelitian dianalisis secara univariat dan bivariat dengan uji spearman rank. Hasil penelitian menunjukkan sebanyak 47,8\% responden menyatakan bahwa peran ayah ASI baik, dimana 67,2\% ibu memberikan ASI secara eksklusif kepada anaknya. Peran ayah ASI mempunyai hubungan positif yang rendah dengan pemberian ASI eksklusif $(p 0,019 ; r 0,287)$. Dapat disimpulkan peran ayah ASI berhubungan dengan pemberian ASI eksklusif, namun dengan korelasi rendah dikarenakan terdapat faktor lain selain peran ayah ASI yang mempengaruhi pemberian ASI eksklusif. Disarankan agar ayah dapat meningkatkan pengetahuan dan perannya sebagai ayah ASI dengan cara mencari informasi terkait peran ayah ASI melalui berbagai media. Selain itu, tenaga kesehatan agar tetap melakukan pemberian informasi terkait pentingnya ASI eksklusif pada ibu dan ayah saat melakukan ANC dan khususnya kepada keluarga, karena keluarga dapat menjadi faktor yang dapat mempengaruhi perilaku pemberian ASI secara eksklusif.
\end{abstract}

Kata kunci: ASI eksklusif, ayah ASI, peran

\section{Abstract}

The coverage of infants who exclusively breastfed in Bandung Regency in 2018 was $50.39 \%$. The mother's success in exclusive breastfeeding can be influenced by the family's support, especially the father who acts as the father of breastfeeding. A breastfeeding father is a father involved in providing support, both morally and materially, to his wife in the breastfeeding process. This study aims to determine the relationship between the role of breastfeeding fathers with exclusive breastfeeding in Independent Practice Midwives (IPM) Bandung Regency. Analytical survey research design with cross-sectional research design. The number of samples as many as 67 respondents, namely mothers who have babies 6-12 months who visited the IPM Bandung Regency. Data collection uses a questionnaire that has been tested for validity and reliability, which is distributed using Google forms through the WhatsApp application. The research data were analyzed by univariate and bivariate with Spearman rank test. The results showed that $47.8 \%$ of respondents stated that the role of breastfeeding fathers was good, where $67.2 \%$ of mothers gave exclusive breastfeeding to their children. The role of breastfeeding fathers has a low positive relationship with exclusive breastfeeding (p 0.019; $r 0.287$ ). It can be concluded that the role of breastfeeding fathers is related to exclusive breastfeeding, but 
with a low correlation because there are other factors besides the role of breastfeeding fathers that affect exclusive breastfeeding. It is suggested that fathers can increase their knowledge and role as breastfeeding fathers by seeking information related to the role of breastfeeding fathers through various media. In addition, health workers should continue to provide information related to the importance of exclusive breastfeeding to mothers and fathers during ANC and especially to families because a family can be a factor that can influence exclusive breastfeeding behavior.

Keywords: exclusive breastfeeding, breastfeeding fathers, role

\section{PENDAHULUAN}

Masalah kesehatan dan gizi pada anak menjadi fokus penting untuk menghasilkan sumber daya manusia yang berkualitas. Modal dasar dalam pembentukan manusia berkualitas dimulai sejak bayi dalam kandungan disertai dengan pemberian Air Susu Ibu (ASI) sejak bayi lahir. Pemberian ASI secara eksklusif sampai usia 6 bulan dan ASI sampai usia dua tahun dapat membantu anak dalam mencapai tumbuh kembang optimal serta melindungi terhadap beberapa penyakit. Manfaat ASI lebih optimal jika pemberian ASI dilakukan secara eksklusif tanpa pemberian makanan tambahan lain sampai dengan usia 6 bulan (Mufdililah, Zufla, \& Johan, 2019).

Data Kementerian Kesehatan tahun 2018 menyebutkan cakupan bayi yang mendapatkan ASI secara eksklusif di Indonesia masih tergolong rendah yaitu $68,74 \%$, sementara itu cakupan ASI eksklusif di Jawa Barat melebihi angka nasional yaitu 90,79\% (Kemenkes RI, 2019). Cakupan bayi yang mendapatkan ASI secara eksklusif di Kabupaten Bandung tahun 2018 sebanyak 19.336 bayi $(50,39 \%)$ dari total 36,376 bayi (Dinkes Kabupaten Bandung, 2018). Hasil cakupan tersebut dapat menjadi salah satu perhatian kenapa cakupan ASI eksklusif di wilayah Kabupaten Bandung masih rendah atau belum berhasil.

Keberhasilan ibu dalam pemberian ASI eksklusif dapat dipengaruhi oleh dukungan dari keluarga terutama dukungan Ayah. Dukungan ayah atau peran Ayah ASI atau disebut juga sebagai Ayah ASI "Breastfeeding Father" merupakan suatu dukungan yang diberikan oleh Ayah kepada istri dalam proses menyusui atau pemberian ASI (Mufdililah et al., 2019). Keberhasilan ASI eksklusif perlu dukungan dari berbagai pihak, baik dari keluarga (ayah, orang tua atau mertua), petugas kesehatan, kader dan lainnya. Dukungan ayah kepada ibu mempunyai peran yang penting dalam pemberian ASI eksklusif karena ayah dari si bayi merupakan orang yang berpengaruh dalam pengambilan keputusan ibu untuk memberikan ASI secara eksklusif atau tidak (Dwiutami, Hartiyanti, \& Jamil, 2015).

Penelitian (Rosyada \& Putri, 2018) menunjukkan bahwa peran ayah berhubungan dengan keberhasilan ASI eksklusif. Dukungan fisik antara sudut pandang ibu dan ayah yang paling tinggi gap nya $(p<0,001)$ sedangkan dukungan yang paling diinginkan ibu adalah dukungan emosional. Penelitian Dwiutami, Hartiyanti, \& Jamil (2015) mengenai "Studi fenomenologi peran ayah terhadap pemberian air susu ibu (ASI) di wilayah Puskesmas Godean II Kabupaten Sleman", menjelaskan, sebagian besar ayah yang mempunyai bayi dengan riwayat ASI eksklusif memberikan dukungan emosional, penilaian positif, instrumental, dan informasional pada istrinya dalam memberikan ASI eksklusif.

Pada kenyataannya keterlibatan Ayah dalam mendukung keberhasilan ASI eksklusif masih kurang, salah satunya karena secara kultural ada pembagian peran dimana Ayah berperan sebagai pencari nafkah dan istri mengurusi 
rumah tangga (Mufdililah et al., 2019). Pendapat tersebut didukung penelitian Nurafifah (2016) mengenai Breastfeeding father terhadap kejadian Postpartum blues yang menyatakan bahwa $66,7 \%$ keterlibatan ayah sebagai Breastfeeding father adalah kurang, dimana 100\% keterlibatan ayah kurang pada masa kehamilan, 100\% pada masa persalinan dan $86,7 \%$ pada masa nifas.

Mengingat pentingnya pemberian ASI eksklusif untuk tumbuh kembang anak, maka dengan adanya dukungan dari Ayah dapat meningkatkan ibu dalam memberikan ASI secara eksklusif. Dukungan dari Ayah mempermudah ibu dalam proses menyusui dimana kondisi mental ibu akan stabil, tidak stress, terhindar dari kelelahan sehingga ibu dapat memberikan ASI terbaik.

Tujuan dari penelitian ini adalah untuk mengetahui gambaran peran ayah ASI dan pemberian ASI eksklusif oleh ibu serta menganalisis derajat hubungan antara peran ayah ASI dengan pemberian ASI eksklusif di Praktik Mandiri Bidan (PMB) Kabupaten Bandung.

\section{METODOLOGI}

Jenis penelitian kuantitatif menggunakan metode survei analitik dengan pendekatan cross-sectional. Populasi penelitian adalah ibu yang mempunyai bayi usia 6-12 bulan yang berkunjungan ke PMB Kabupaten Bandung, antara lain PMB Imas Masdinarsyah, PMB Lena, PMB Enjah, PMB Nuryani, dan PMB Shelly Fitria. Penentuan lokasi PMB pada penelitian ini dilakukan secara acak. Bidan yang bersedia lahan praktiknya (PMB) untuk dijadikan sebagai tempat penelitian serta bersedia menyebarkan link google form kepada subjek penelitian dijadikan sebagai lokasi penelitian.

Jumlah sampel yang digunakan dalam penelitian ini yaitu sebanyak 67 responden ibu yang mempunyai bayi usia 6-12 bulan yang berkunjungan ke 5 PMB. Teknik sampling untuk menentukan responden penelitian menggunakan non-probability sampling yang diambil secara accidental sampling (Riyanto, 2019). Jadi pada penelitian ini, subjek yang sesuai dengan kriteria penelitian yang kebetulan ada dan bersedia menjadi responden penelitian dijadikan sebagai sampel. Kriteria inklusi dalam penelitian ini adalah:

a. Ibu menyusui bayi usia 6-12 bulan

b. Ibu yang bertempat tinggal di wilayah Kabupaten Bandung.

c. Ibu yang Ayahnya tidak bekerja di luar kota

d. Orang tua tinggal serumah

Adapun yang menjadi kriteria eksklusi pada penelitian ini adalah:

a. Ibu yang tidak bisa menyusui karena faktor penyakit (patologis) atau infeksi seperti kanker payudara.

b. Ibu yang terpisah dari bayi nya

c. Subjek yang tidak bersedia menjadi responden penelitian.

Penelitian ini menggunakan data primer yang didapat langsung dari responden menggunakan angket berupa kuesioner untuk mengukur peran Ayah ASI dan pemberian ASI eksklusif. Pengukuran data ASI eksklusif menggunakan kuesioner lembar check list. Pengukuran peran Ayah ASI menggunakan kuesioner yang diadopsi dari Buku Panduan Ayah ASI (Mufdililah et al., 2019). Skala yang digunakan adalah skala Likert dengan skor 1-4 terdiri dari empat alternatif jawaban, yaitu "Selalu (SL)", "Sering (SR)", "Jarang (J)", dan "Tidak Pernah (TP)". Jumlah item soal sebanyak 35 soal (sebelum uji validitas) dan menjadi 30 soal (setelah uji validitas).

Pada tahap pengumpulan data penelitian ini, peneliti menggunakan kuesioner yang disebarkan dengan Google form melalui aplikasi WhatsApp, dimana setiap bidan PMB memberikan link kepada responden untuk 
mengakses Google form tersebut dan mengisi data-data serta pertanyaan dari kuesioner yang telah disediakan.

Analisis data dilakukan secara univariat dan bivariat. Analisis univariat (deskriptif) bertujuan mendeskripsikan setiap variabel, dimana data disajikan dalam bentuk tabel distribusi frekuensi dan persentase. Analisis bivariat bertujuan untuk menguji hipotesis hubungan peran Ayah ASI dengan pemberian ASI eksklusif. Pengujian hipotesis pada analisis bivariat ini menggunakan uji spearman rank dikarenakan skala ukur yang digunakan adalah skala ordinal-nominal (Dahlan, 2019).

\section{HASIL}

Berikut disajikan data hasil penelitian mengenai gambaran peran ayah ASI yang dipersepsikan oleh ibu, gambaran pemberian ASI eksklusif, dan hubungan peran ayah ASI dengan pemberian ASI eksklusif pada 67 responden yaitu ibu yang mempunyai bayi usia 6-12 bulan.
Tabel 1. Distribusi Frekuensi Gambaran Peran Ayah ASI

\begin{tabular}{|c|c|c|}
\hline Peran Ayah ASI & $\mathbf{f}$ & $\%$ \\
\hline Kurang Baik & 35 & 52,2 \\
\hline Baik & 32 & 47,8 \\
\hline Total & 67 & 100 \\
\hline
\end{tabular}

Pada tabel 1 menunjukkan bahwa dari 67 responden, sebanyak 52,2\% ibu menyatakan bahwa peran ayah ASI kurang baik.

Tabel 2. Distribusi Frekuensi Gambaran Pemberian ASI Eksklusif

\begin{tabular}{lccc}
\hline \multicolumn{2}{c}{$\begin{array}{c}\text { Pemberian ASI } \\
\text { Eksklusif }\end{array}$} & f & \% \\
\hline Tidak & & 22 & 32,8 \\
Ya & Total & 45 & 67,2 \\
\hline \multicolumn{2}{c}{} & $\mathbf{6 7}$ & $\mathbf{1 0 0}$ \\
\hline
\end{tabular}

Pada tabel 2 menunjukkan bahwa dari 67 responden, sebanyak $67,2 \%$ ibu memberikan ASI secara eksklusif pada bayinya hingga usia 6 bulan.

Tabel 3. Hubungan Peran Ayah ASI dengan Pemberian ASI Eksklusif

\begin{tabular}{|c|c|c|c|c|c|c|c|c|}
\hline \multirow{3}{*}{ Peran Ayah ASI } & \multicolumn{4}{|c|}{ Pemberian ASI Eksklusif } & \multirow{2}{*}{\multicolumn{2}{|c|}{ Total }} & \multirow{3}{*}{ p-value } & \multirow{3}{*}{$\mathbf{r}$} \\
\hline & \multicolumn{2}{|c|}{ Tidak } & \multicolumn{2}{|c|}{ Ya } & & & & \\
\hline & f & $\%$ & $\mathbf{f}$ & $\%$ & f & $\%$ & & \\
\hline Kurang Baik & 16 & 45,7 & 19 & 54,3 & 35 & 100 & & \\
\hline Baik & 6 & 18,8 & 26 & 81,3 & 32 & 100 & $0,019 *$ & 0,287 \\
\hline Total & 22 & 32,8 & 45 & 67,2 & 67 & 100 & & \\
\hline
\end{tabular}

*Uji spearman rank

Pada tabel 3 menunjukkan bahwa dari 35 responden yang menyatakan peran ayah ASI kurang baik sebanyak 16 responden $(45,7 \%)$ tidak memberikan ASI secara eksklusif. Diketahui dari 32 responden yang menyatakan peran ayah ASI baik sebanyak 26 responden $(81,3 \%)$ memberikan ASI secara eksklusif. Hasil uji statistik didapatkan nilai p $0,019<\alpha 0,05$ sehingga Ho ditolak yang artinya ada hubungan antara peran ayah ASI dengan pemberian
ASI eksklusif. Didapatkan nilai r 0,287 yang artinya peran ayah ASI terhadap pemberian ASI eksklusif mempunyai hubungan yang positif namun dengan kekuatan atau tingkat korelasi yang rendah.

\section{PEMBAHASAN}

Peran ayah ASI menjadi salah satu faktor penting dalam menyukseskan program 
ASI eksklusif. Data hasil penelitian mengenai gambaran peran ayah ASI diketahui bahwa responden menyatakan peran ayah ASI kurang baik sebanyak 35 responden $(52,2 \%)$ dan responden menyatakan peran ayah ASI baik sebanyak 32 responden (47,8\%). Hal ini menjelaskan, suami kurang dapat berperan baik menjadi ayah ASI. Hasil penelitian ini didukung penelitian (Wardani, 2017) yang menjelaskan $84,9 \%$ responden menyatakan peran ayah ASI kurang baik atau rendah.

Masih rendahnya peran ayah ASI ini dapat dipengaruhi oleh berbagai faktor, seperti pendidikan. Berdasarkan data hasil penelitian, diketahui dari 35 responden dengan peran ayah ASI kurang baik, sebanyak 8 responden $(88,9 \%)$ berpendidikan SLTP/ MTs, dan 3 responden (100\%) berpendidikan tinggi seluruhnya mempunyai peran ayah ASI baik. Hasil tersebut menjelaskan pendidikan berhubungan dengan peran ayah ASI.

Tingkat pendidikan dapat mempengaruhi penerimaan suatu pengetahuan maupun dalam melakukan suatu hal. Pendidikan yang rendah dapat menyebabkan pengetahuan yang rendah sehingga mempengaruhi dalam mengakses atau menerima informasi. Hal ini berdampak pada kekurangefektifan ayah untuk mengambil keputusan dalam mendukung pemberian ASI eksklusif (Mufdililah et al., 2019).

AyahyangberperansebagaiayahASIdapat memberikan dukungan positif, seperti dengan cara memotivasi istri untuk tetap memberikan ASI secara eksklusif, memberikan pujian, memberikan sugesti yang positif, menunjukkan kasih sayang dan simpati, menciptakan suasana nyaman, memberikan waktu kepada istri untuk beristirahat, meluangkan waktu bersama istri dan lain sebagainya (Mufdililah et al., 2019).

Tujuan dari ayah ASI adalah untuk menyukseskan pemberian ASI eksklusif kepada bayi sejak bayi lahir sampai usia 6 bulan dan dilanjutkan dengan ASI partial sampai usia 2 tahun. Untuk mewujudkan tujuan tersebut, dibutuhkan kesadaran tentang pentingnya peran ibu dan ayah dalam pemberian ASI eksklusif serta kerjasama yang solid antara ibu dan ayah selama proses menyusui. Pemahaman yang benar tentang ASI eksklusif serta peran ibu dan ayah dalam memberikan ASI eksklusif kepada bayinya diharapkan dapat membentuk ayah menjadi partner ASI yang ideal (Mufdililah et al., 2019).

Berdasarkan data hasil penelitian mengenai gambaran pemberian ASI eksklusif di Praktik Mandiri Bidan (PMB) Kabupaten Bandung sebanyak 67,2\% memberikanASI secara eksklusif, sedangkan hanya 32,8\% ibu yang tidak memberikan ASI secara eksklusif pada bayinya hingga usia 6 bulan. Hasil tersebut menjelaskan bahwa ibu di PMB Kabupaten Bandung hanya sebagian besar yang memberikan ASI secara eksklusif sampai usia 6 bulan, dan masih terdapat beberapa ibu yang tidak memberikan ASI secara eksklusif sampai usia 6 bulan.

Berdasarkan hasil penelitian dari 22 ibu, sebanyak 18 ibu $(81,8 \%)$ memberikan ASI sampai usia $<6$ bulan. Selain itu diketahui bahwa dari $22 \mathrm{ibu}$, sebanyak 5 ibu memberikan madu, air putih, air tajin atau yang lainnya pada minggu-minggu awal setelah melahirkan bayi dengan alasan mengikuti saran dari orang tua.

Peraturan Pemerintah Nomor 33 Tahun 2012 tentang Pemberian Air Susu Ibu Eksklusif menjelaskan ASI eksklusif merupakan ASI yang diberikan selama 6 bulan kepada bayi sejak dilahirkan sampai usia 6 bulan, tanpa menambahkan dan/atau mengganti ataupun memberikan makanan atau minuman lain (kecuali obat, vitamin, dan mineral) (Kemenkes RI, 2019).

Pemberian ASI eksklusif mempunyai berbagai manfaat yang sangat luas dan beragam terutama manfaat bagi ibu dan bayi serta keluarga. Dampak bayi yang tidak diberikan ASI maupun 
ASI secara eksklusif yaitu bayi dapat mengalami daya tahan tubuh tidak optimal, perkembangan orak, gigi dan rahang menjadi kurang, dampak psikologis kedekatan dengan ibu berkurang, dan sering timbul alergi serta ruam (Khasanah, 2011).

Kegagalan pemberian ASI eksklusif dapat disebabkan oleh berbagai faktor, seperti masalah kesehatan pada ibu dan bayi, anggapan ASI saja tidak cukup sehingga harus diberikan makanan tambahan lain, anak rewel, ibu yang bekerja, usia orang tua, serta pengetahuan orang tua dan dukungan dari keluarga yang kurang (Mufdililah et al., 2019).

Berdasarkan data hasil penelitian pengujian hipotesis, dapat diketahui bahwa ada hubungan antara peran ayah ASI dengan pemberian ASI eksklusif di Praktik Mandiri Bidan (PMB) Kabupaten Bandung. Peran ayah ASI mempunyai hubungan positif yang rendah terhadap pemberian ASI eksklusif. Hasil tersebut menunjukkan bahwa peran ayah ASI dapat berkaitan dengan pemberian ASI secara eksklusif.

Hasil penelitian ini didukung penelitian (Rosyada \& Putri, 2018) yang menjelaskan bahwa terdapat hubungan peran ayah ASI dengan keberhasilan praktik ASI eksklusif di wilayah kerja Puskesmas 23 Ilir Kota Palembang. Hal yang sama dengan penelitian (Rahmadhona, Affarah, Wiguna, \& Reditya, 2017) yang menjelaskan bahwa peran suami berpengaruh terhadap keberhasilan pemberian ASI Eksklusif di Kota Mataram.

Penelitian (Retno, Nursalam, \& Rahmat, 2016) menjelaskan bahwa dukungan ayah dan interaksi ayah berpengaruh terhadap proses menyusui ibu. Semakin besar dukungan ayah baik secara moril maupun materil saat proses menyusui maka dapat meningkatkan peluang ibu untuk memberikan ASI secara eksklusif. Penelitian (Yanti, 2021) menjelaskan bahwa dukungan ayah (baik secara finansial, fisik dan emosional) sepanjang masa kehamilan hingga 6 bulan masa menyusui tanpa ada satu periode pun yang terlewat berhubungan dengan keberhasilan ASI eksklusif $(p=0,013)$.

Adanya hubungan antara peran ayah ASI dengan pemberian ASI eksklusif di Praktik Mandiri Bidan (PMB) Kabupaten Bandung tersebut dapat terlihat dari data hasil penelitian dimana $81,3 \%$ responden yang menyatakan peran ayah ASI baik memberikan ASI secara eksklusif, sedangkan $45,7 \%$ responden yang menyatakan peran ayah ASI kurang baik tidak memberikan ASI secara eksklusif. Hal ini menjelaskan bahwa Semakin baik peran ayah ASI akan meningkatkan peluang ibu untuk memberikan ASI secara eksklusif sampai usia 6 bulan.

Peran Ayah ASI mempunyai andil penting dalam pemberian ASI secara eksklusif. Ayah atau suami memiliki peran besar terhadap keberhasilan ASI eksklusif. Ayah atau suami dapat lebih memberikan dukungan khususnya emosional kepada ibu saat menyusui seperti dengan memuji, tidak memberikan kritik terhadap bentuk tubuh, serta membahagiakan hati atau perasaan ibu sehingga hormon oksitosin ibu dapat diproduksi dengan lancar yang membuat ASI keluar dengan lancar (Rosyada \& Putri, 2018).

Manfaat dari pemberian ASI bagi ayah yang mendukung istrinya untuk menyusui dengan ASI dan bahkan dapat mensukseskan ASI secara eksklusif yaitu tidak perlu membeli susu formula. Hal ini dapat berdampak pada penghematan besar bagi ekonomi rumah tangga. Selain itu Ayah yang mendukung dalam pemberian ASI dapat meningkatkan jalinan kasih sayang antara ayah dan bayi (Lim, 2007).

Peran Ayah ASI yang baik memperbesar peluang untuk keberhasilan ibu memberikan ASI secara eksklusif kepada bayinya sebesar 11,37 kali. Peran Ayah dalam hal ini mencakup dukungan emosional, dukungan instrumental, dukungan fisik, dan dukungan informasi. Jika 
semua elemen dukungan ini terpenuhi peluang ibu untuk mencapai keberhasilan ASI eksklusif akan meningkat. Peran Ayah ini memiliki kaitan dengan tingkat stress ibu. Jika peran ayah terhadap menyusui ibu baik maka akan berbanding terbalik dengan tingkat stress ibu yang menurun (Rosyada \& Putri, 2018).

Peran ayah mempunyai pengaruh cukup kuat dalam proses menyusui atau pemberian ASI. Walaupun demikian, pada kenyataannya masih terdapat ayah yang belum menerapkan perannya sebagai ayah ASI dalam proses menyusui. Hal tersebut dapat dikarenakan pengetahuan ayah yang masih kurang atau rendah serta adanya anggapan bahwa menyusui hanya menjadi tanggung jawab ibu saja (Rahmawati, 2016). Maka dari itu, peningkatan pengetahuan dan pemberian edukasi kepada ayah menjadi salah satu faktor yang dapat meningkatkan peran ayah sebagai ayah ASI.

\section{SIMPULAN DAN SARAN}

Berdasarkan hasil penelitian, dapat diketahui bahwa sebanyak $47,8 \%$ responden menyatakan peran ayah ASI baik. Diketahui sebanyak 67,2\% ibu memberikan ASI secara eksklusif kepada bayinya. Terdapat hubungan positif yang rendah antara peran ayah ASI dengan pemberian ASI eksklusif (p 0,019; r 0,287). Semakin baik peran ayah ASI akan meningkatkan peluang ibu untuk memberikan ASI secara eksklusif sampai usia 6 bulan.

Disarankan para ayah dapat meningkatkan perannya sebagai ayah ASI dengan cara meningkatkan pengetahuan maupun mencari informasi terkait ayah ASI memalui berbagai media. Selain itu, tenaga kesehatan disarankan agar tetap melakukan edukasi atau pemberian informasi terkait pentingnya ASI eksklusif khususnya kepada keluarga, karena keluarga dapat menjadi faktor yang dapat memengaruhi perilaku pemberian ASI secara eksklusif.

\section{DAFTAR PUSTAKA}

Dahlan, M. S. (2019). Statistik untuk Kedokteran dan Kesehatan: Deskriptif, Bivariat, dan Multivariat Dilengkapi Aplikasi dengan Menggunakan SPSS (5th ed., Vol. 1). Jakarta: Epidemiologi Indonesia.

Dinkes Kabupaten Bandung. (2019). Profil Kesehatan Kabupaten Bandung Tahun 2018.

Dwiutami, H., Hartiyanti, Y., \& Jamil, M. D. (2015). Studi Fenomenologi: Peran Ayah Terhadap Pemberian Air Susu Ibu (ASI) dan Status Gizi Bayi Di Wilayah Puskesmas Godean II Kabupaten Sleman (UGM). UGM, Yogyakarta. Retrieved from etd.repository.ugm.ac.id/penelitian/ detail/85556\#abstrak

Kemenkes RI. (2019). Profil Kesehatan Indonesia 2018. Jakarta: Kemenkes RI.

Khasanah, N. (2011). ASI atau Susu Formula ya ? Yogyakarta: FlashBook.

Lim, R. (2007). “ASI Eksklusif Dong!” Buku untuk para Bapak (Edisi Pert; T. Suriajaya, Trans.). Bali: Yayasan Bumi Sehat; Half Angel Press.

Mufdililah, Zufla, S. Z., \& Johan, R. B. (2019). Buku Panduan Ayah ASI. Yogyakarta: Nuha Medika.

Nurafifah, D. (2016). Ayah ASI (Breastfeeding Father) Terhadap Kejadian Postpartum Blues. RAKERNAS AIPKEMA 2016: Temu Ilmiah Hasil Penelitian Dan Pengabdian Masyarakat, 75-81.

Rahmadhona, D., Affarah, W. S., Wiguna, P. A., \& Reditya, N. M. (2017). Faktor-Faktor yang Mempengaruhi Keberhasilan Pemberian ASI Eksklusif di Kota Mataram. Jurnal Kedokteran Unram, 6(2), 1-16.

Rahmawati, A. (2016). Optimalisasi Peran Ayah ASI (Breastfeeding Father) Melalui Pemberian Edukasi Ayah Prenatal. 
Jurnal Ners Dan Kebidanan (Journal of Ners and Midwifery), 3(2), 101-106. doi: 10.26699/jnk.v3i2.art.p101-106

Retno, S., Nursalam, \& Rahmat, B. (2016). Peran Ayah Dalam Keberhasilan Program Inisiasi Menyusui Dini (IMD) Pada Bayi Yang Lahir Secara Sectio Cesaria. Jurnal Ners, 11(2), 224-229.

Riyanto, A. (2019). Aplikasi Metodologi Penelitian Kesehatan: Dilengkapi Contoh Kuesioner dan Laporan Penelitian. Yogyakarta: Nuha Medika.

Rosyada, A., \& Putri, D. A. (2018). Peran Ayah ASI Terhadap Keberhasilan Praktik ASI
Eksklusif Di Wilayah Kerja Puskesmas 23 Ilir Kota Palembang. Jurnal Berkala Kesehatan, 4(2), 70. doi: 10.20527/jbk. v4i2.5497

Wardani, T. (2017). Hubungan Peran Ayah ASI Dengan Pemberian Asi Eksklusif Di Wilayah Kerja Puskesmas Dlingo I Yogyakarta. Universitas Jenderal Achmad Yani, Yogyakarta. Retrieved from http:// repository.unjaya.ac.id/2040/

Yanti, E. S. (2021). Dukungan Ayah ASI terhadap Keberhasilan ASI Eksklusif. Muhammadiyah Journal of Midwifery, 1(2), 67. doi: 10.24853/myjm.1.2.67-74 